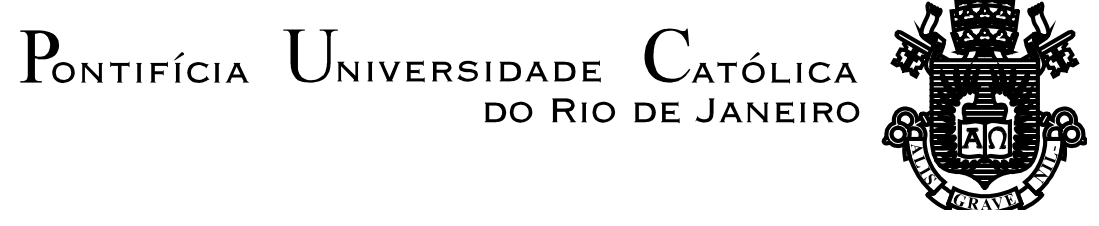

Larissa Rangel Ferrari

\title{
O PROCESSAMENTO SINTÁTICO EM IDOSOS: COMPREENSÃO DE SENTENÇAS AMBÍGUAS E CORRELAÇÃO COM FUNÇÕ̃ES EXECUTIVAS
}

Dissertação apresentada ao Programa de Pós-graduação em Estudos da Linguagem da PUC-Rio como requisito parcial para obtenção do grau de Mestre em Letras/Estudos da Linguagem.

Orientadora: Profa. Erica dos Santos Rodrigues Coorientador: Prof. Daniel Correa Mograbi 
Pontifícia Universidade Católica $_{\text {Do Rio de Janeiro }}$

Larissa Rangel Ferrari

\section{O PROCESSAMENTO SINTÁTICO EM IDOSOS: COMPREENSÃO DE SENTENÇAS AMBÍGUAS E CORRELAÇÃO COM FUNÇỖES EXECUTIVAS}

Dissertação apresentada como requisito parcial para obtenção do grau de Mestre pelo Programa de Pós-graduação em Estudos da Linguagem da PUC-Rio. Aprovada pela Comissão Examinadora abaixo assinada.

Profa. Erica dos Santos Rodrigues

Orientadora

Departamento de Letras - PUC-Rio

Prof. Daniel Correa Mograbi

Coorientador

Departamento de Psicologia - PUC-Rio

Profa. Letícia Maria Sicuro Corrêa

Departamento de Letras - PUC-Rio

Prof. Jerson Laks

UFRJ

Profa. Monah Winograd

Coordenadora Setorial do Centro de Teologia

e Ciências Humanas - PUC-Rio

Rio de Janeiro, 20 de abril de 2017. 
Todos os direitos reservados. É proibida a reprodução total ou parcial do trabalho sem autorização da universidade, da autora e do orientador.

\section{Larissa Rangel Ferrari}

Graduou-se em Comunicação Social - Jornalismo pela PUC-Rio em 2012 e também em Letras (Português-Italiano e Respectivas Literaturas) pela Universidade do Estado do Rio de Janeiro (Uerj) em 2014. Tem atuado na área de Linguística, com ênfase em Psicolinguística e Teoria Linguística.

Ficha catalográfica

Ferrari, Larissa Rangel

O processamento sintático em idosos: compreensão de sentenças ambíguas e correlação com funções executivas / Larissa Rangel Ferrari; orientadora: Erica dos Santos Rodrigues; co-orientador: Daniel Correa Mograbi. - 2017.

128 f.: il. color. ; $30 \mathrm{~cm}$

Dissertação (mestrado) - Pontifícia Universidade Católica do Rio de Janeiro, Departamento de Letras, 2017.

Inclui bibliografia

1. Letras - Teses. 2. Processamento sintático. 3. Idosos. 4. Funções executivas. 5. Garden-path. 6. Good-enough. I. Rodrigues, Erica dos Santos. II. Mograbi, Daniel Correa. III. Pontifícia Universidade Católica do Rio de Janeiro. Departamento de Letras. IV. Título.

CDD: 400 


\section{Agradecimentos}

À minha orientadora Professora Erica dos Santos Rodrigues, pela empenhada dedicação, por toda disponibilidade oferecida e pelo estímulo e trabalho que me inspiram demasiadamente nesta trajetória da pós-graduação.

Ao meu coorientador Daniel Correa Mograbi, por todo incentivo, apoio e disponibilidade em me ajudar para realizar a articulação crucial deste trabalho.

Ao CNPq e à PUC-Rio, pelos auxílios concedidos, sem os quais este trabalho não poderia ter sido realizado.

Aos professores participantes da banca examinadora, Letícia Maria Sicuro Corrêa e Jerson Laks, que fizeram parte de um momento muito importante nesta trajetória e ofereceram seu precioso olhar sobre meu trabalho.

À professora Cilene Aparecida Nunes Rodrigues, por toda atenção, incentivo, conselhos e sugestões importantes.

Aos meus pais Edson e Marisa, base de tudo, por todo amor, incentivo e força que sempre me deram, por acreditarem em meu potencial, porque sem eles nada disso seria possível.

Ao meu namorado Gabriel, pela compreensão e engajamento com meu trabalho, por se disponibilizar integralmente para me ajudar sempre em qualquer momento, inclusive nos mais difíceis, por todo carinho e apoio imensuráveis.

À minha tia Márcia e ao meu tio João Paulo, que foram extremamente generosos comigo no auxílio à realização da minha pesquisa e foram fundamentais para a concretização deste trabalho. 
Às minhas colegas de mestrado Monica e Leslie, pela amizade e por estarem sempre dispostas a ajudar quando preciso.

Ao meu irmão Brenno, à minha prima Juliana e às minhas amigas Isabella, Denise, Mitali, Anabelle, Patricia, Carol, Bel, Luar e Laís, que se solidarizaram para me ajudar na condução desta pesquisa.

A todas as outras pessoas não mencionadas aqui, mas que, de alguma forma, me ajudaram também na conclusão deste trabalho.

Cabe também destacar que a professora Letícia foi quem me introduziu à Psicolinguística, quando me recebeu gentilmente em seu laboratório e me proporcionou a riquíssima oportunidade de estagiar nele. Sou muito grata. 


\section{Resumo}

Ferrari, Larissa Rangel; Rodrigues, Erica dos Santos (Orientadora); Mograbi, Daniel Correa (Coorientador). O processamento sintático em idosos: compreensão de sentenças ambíguas e correlação com funções executivas. Rio de Janeiro, 2017, 128p. Dissertação de Mestrado Departamento de Letras, Pontifícia Universidade Católica do Rio de Janeiro.

Esta dissertação se insere na área da Psicolinguística, em articulação com a Neuropsicologia. A pesquisa se voltou para a investigação, em idosos hígidos, do processamento sintático de sentenças envolvendo ambiguidade temporária (ex.: "Enquanto o homem cozinhava a batata era comprada no mercado"), as quais induzem ao efeito labirinto (garden-path effect). O objetivo deste trabalho foi compreender em que medida um declínio de funções executivas com o avanço da idade poderia afetar o processamento desse tipo de estrutura sintática, a qual apresenta alta demanda para a memória de trabalho e parece requerer inibição de uma representação mental inicialmente possível. A pesquisa consistiu na aplicação de um experimento psicolinguístico de compreensão por leitura e testes de avaliação neuropsicológica (Span de Digítos, Stroop e Miniexame do Estado Mental, este último aplicado apenas aos idosos). No experimento psicolinguístico, foram tomadas como variáveis intrassujeitos plausibilidade e extensão da região ambígua entre o sintagma nominal crítico ("a batata”) e o ponto de desambiguização da sentença ("era comprada"). Foram testados 40 participantes (20 idosos e 20 jovens). Houve um efeito principal de plausibilidade e extensão da região ambígua e um efeito de interação entre grupo e plausibilidade, tendo os idosos apresentado maior dificuldade, nas condições plausíveis, para inibir a estrutura sintática equivocada construída inicialmente. Também observamos uma correlação entre plausibilidade e o teste Stroop. Os resultados são discutidos em termos da abordagem Good-Enough da compreensão da linguagem e de questões pertinentes às relações entre linguagem e outros domínios da cognição, em especial o papel de funções executivas no processamento sintático.

\section{Palavras-chave}

processamento sintático; idosos; funções executivas; efeito garden-path; processamento good-enough; memória de trabalho; controle inibitório 


\section{Abstract}

Ferrari, Larissa Rangel; Rodrigues, Erica dos Santos (Advisor); Mograbi, Daniel Correa (Co-advisor). Syntactic processing in the elderly: comprehension of ambiguous sentences and correlation with executive functions. Rio de Janeiro, 2017, 128p. Dissertação de Mestrado Departamento de Letras, Pontifícia Universidade Católica do Rio de Janeiro.

This master's thesis is situated within the area of psycholinguistics, in conjunction with neuropsychology, and investigates syntactic processing of temporarily ambiguous sentences in the elderly ("While the man cooked the potatoes were bought at the supermarket."). These structures induce the gardenpath effect. The purpose of the work was to analyze to what extent a decline in executive functions with advancing age could affect syntactic processing of syntactic ambiguity, which presents a high demand for working memory and seems to require inhibition of an initially possible mental representation. The research consisted in the application of a psycholinguistic experiment (a reading comprehension task) and neuropsychological evaluation tests (Digit Span, Stroop and Mini-Mental State Examination; the latter was only applied to the group of older participants). In the psycholinguistic experiment, plausibility and the distance between the critical noun phrase ("the potato") and the point of disambiguation of the sentence ("was bought") were taken as within-subjects variables. Forty participants (20 older adults and 20 young adults) were tested. A main effect of plausibility and distance and an interaction effect between group and plausibility were observed. The elderly showed more difficulty in inhibiting the initial misinterpretation when the sentence was plausible. There was also a correlation between plausibility and the Stroop test. The results are discussed in terms of the Good-Enough Approach to language comprehension and the relationship between language and other domains of cognition, especially the role of executive functions in syntactic processing.

\section{Keywords}

syntactic processing; elderly; executive functions; garden-path effect; goodenough processing; working memory; inhibitory control 


\section{Sumário}

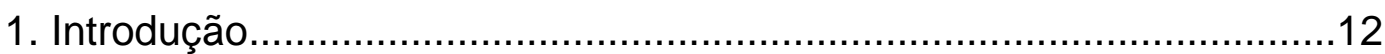

1.1. Apresentação e justificativa..................................................12

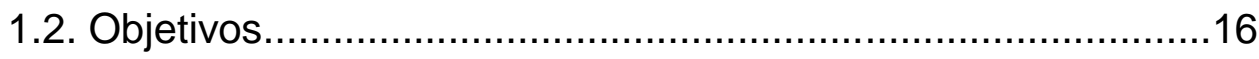

1.3. Hipótese de trabalho.........................................................17

1.4. Possíveis contribuições da pesquisa.......................................18

1.5. Organização do trabalho.....................................................19

2. Aspectos gerais da linguagem no envelhecimento................................20

2.1. Aspectos neurológicos.........................................................21

2.2. Desempenho linguístico: aspectos semânticos, lexicais e

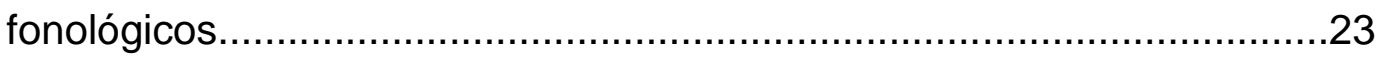

2.3 Desempenho linguístico: aspectos sintáticos...........................26

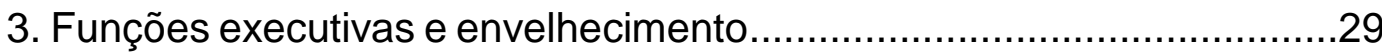

3.1. Breve introdução sobre as funções executivas.........................29

3.2. Correlações entre funções executivas e envelhecimento..........35

3.3. A linguagem e as funções executivas no envelhecimento.........40

4. O processamento sintático de sentenças ambíguas..............................46

4.1. Breve introdução sobre parsing e o efeito Garden-Path...........46

4.2. Abordagem Good-Enough para compreensão da linguagem..54

4.3. Estudos sobre processamento Good-Enough com falantes de Português Brasileiro 59

4.4. Estudos sobre processamento Good-Enough em idosos.........62

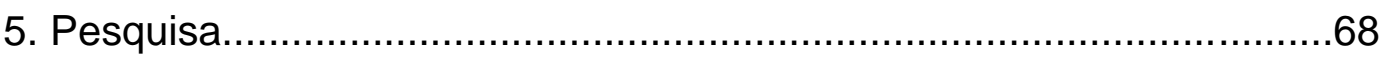

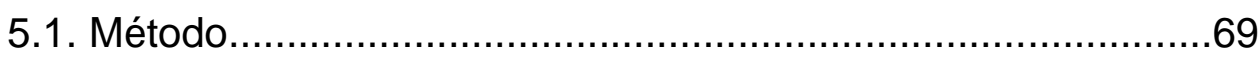

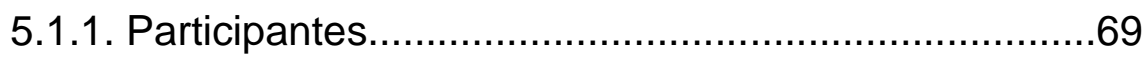

5.1.2. Experimento sobre processamento good-enough......70

5.1.3. Design...................................................................

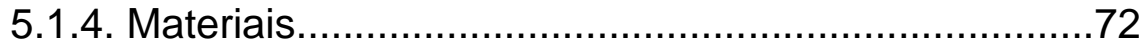

5.1.5. Procedimento e aparato................................................74

5.1.6. Avaliação neuropsicológica.......................................76

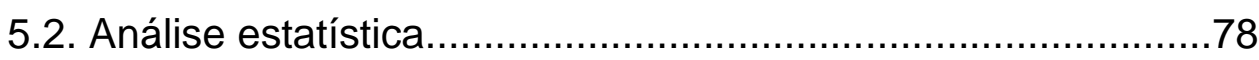

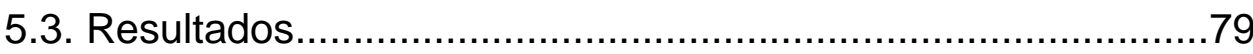




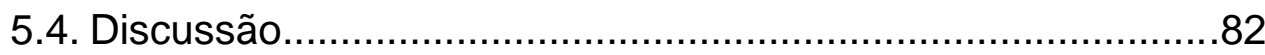

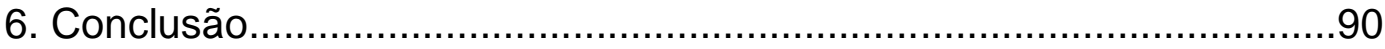

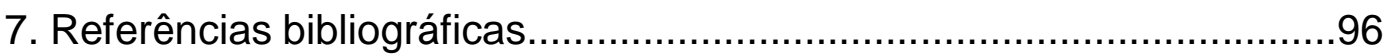

Apêndice 1 - Termo de consentimento livre e esclarecido........................113

Apêndice 2 - Questionário sociodemográfico........................................115

Apêndice 3 - Frases experimentais e distratoras....................................120 


\section{Lista de figuras}

Figura 1 - O cérebro durante compreensão e produção da linguagem......22

Figura 2 - Modelo inicial de memória de trabalho de Baddeley \& Hitch......32

Figura 3 - Modelo revisado de memória de trabalho................................33

Figura 4 - Representações estruturais de sentença com ambiguidade temporária.

Figura 5 - Árvore sintática da sentença quando SN é processado como sujeito

Figura 6 - Árvore sintática da sentença quando o SN é processado como objeto direto 86 


\section{Lista de gráficos}

Gráfico 1 - Média total de acertos nas condições plausível e implausível..80

Gráfico 2 - Média total de acertos nas condições curta e longa. .81

Gráfico 3 - Média total de acertos por plausibilidade, extensão e grupo.

Gráfico 4 - Média total de acertos nas condições plausível e implausível por grupo. .82 